\title{
The Father-Child Activation Relationship, Sex Differences, and Attachment Disorganization in Toddlerhood
}

\author{
Daniel Paquette ${ }^{1}$ and Caroline Dumont ${ }^{2}$ \\ ${ }^{1}$ École de Psychoéducation, Université de Montréal, Case postale 6128, Succursale Centre-Ville, Montréal, QC, Canada H3C 3J7 \\ ${ }^{2}$ Département de Psychologie, Université de Montréal, Case postale 6128, Succursale Centre-Ville, Montréal, QC, Canada H3C 3J7 \\ Correspondence should be addressed to Daniel Paquette; daniel.paquette@umontreal.ca
}

Received 13 November 2012; Revised 7 February 2013; Accepted 16 March 2013

Academic Editor: Helena R. Slobodskaya

Copyright (C) 2013 D. Paquette and C. Dumont. This is an open access article distributed under the Creative Commons Attribution License, which permits unrestricted use, distribution, and reproduction in any medium, provided the original work is properly cited.

\begin{abstract}
The activation relationship theory serves as a complement to Bowlby's attachment theory to better understand the impact of fathering on child development, focusing primarily on parental stimulation of risk taking and control during children's exploration. The first aim of this study was to confirm that the activation relationship as assessed with the observational procedure, the Risky Situation, is primarily determined by paternal stimulation of risk taking as assessed by questionnaire. The second aim was to verify the link between the activation relationship and attachment disorganization. The third aim was to verify the existence of a sex difference in father-toddler dyad activation relationships. The Strange Situation procedure and the Risky Situation procedure were conducted with 58 father-toddler dyads. Fathers completed questionnaires on child temperament and parental behavior. Paternal stimulation of risk taking explains activation once child sex and temperament, the attachment relationship, and emotional support are taken into account. Moreover, there is no relation between the father-child activation relationship and attachment disorganization. Finally, data confirm the existence of a sex difference in the activation relationship in toddlers: fathers activate their sons more than their daughters.
\end{abstract}

\section{Introduction}

Little data on father-child attachment has been collected, at least insofar as young children are concerned. What data we do possess has been obtained through the use of the Strange Situation, a method validated with mothers and used primarily with fathers who are secondary attachment figures for their children. The low stability, low transmissibility, and low predictability of father-child attachment have caused increasing numbers of researchers to question the pertinence of using the Strange Situation with fathers who have little involvement in daily caregiving [1-3]. Grossmann and Grossmann [4] and Grossmann et al. [5], for example, have suggested finding a more appropriate method to assess father-child attachment. Others agree that this relationship develops through mechanisms that may be different from those involved in mother-child attachment [6-10]. In fact, fathers' activities with their children are often unlike from those of mothers: fathers tend to excite children and to engage in more physical play with them than mothers do, especially with boys [11, 12]. According to Labrell [13], children must learn to respond to unforeseen events and it is fathers who facilitate such learning by teasing them and destabilizing them with creative, unconventional games. Fathers act as catalysts for risk taking [14], inciting children to take the initiative in unfamiliar situations, explore, take chances, overcome obstacles, be braver in the presence of strangers, and stand up for themselves. Grossmann et al. [15] have shown that paternal sensitivity in play situations with two-year-old children is a better predictor of attachment 14 years later than the father-child Strange Situation.

Drawing on this literature, Paquette [16, 17] theorized father-child attachment by developing the concept of the "activation relationship," that is, the affective bond that enables children to open up to the outside world, focusing primarily on parental stimulation of risk taking and control. 
According to the attachment theory, children's feelings of confidence result from parental sensitivity to children's comfort seeking in times of distress (secure base), with parents protecting their children by maintaining a close distance between parent and child. According to the activation theory, however, children's feelings of confidence result from parental encouragement of risk-taking during children's exploration of their environment, with parents protecting their children through discipline (limit setting, control).

Paquette and Bigras [18] have developed the Risky Situation (RS), a standardized procedure designed to assess the quality of the parent-child activation relationship in children ages 12 to 18 months, and validated with both fathers and mothers. As proposed by Grossmann et al. [5], we make a distinction between attachment in the broad sense of the term and attachment in the strict sense. Broadly speaking, the attachment relationship refers to the emotional bond between adult and child that is the result of daily interaction and ensures a form of protection for the child (psychological security). The attachment relationship in the strict sense of the term concerns the child's secure base as evaluated by the Strange Situation [19], while the activation relationship concerns the security of exploration [5] as evaluated by the Risky Situation [18]. Like the Strange Situation (SS; [19]), the RS is a twenty-minute-long observational procedure that takes place in an unfamiliar room with toys and in the presence of a stranger. While the SS is divided into eight episodes including two separations from the parent, the RS is divided into six structured episodes during which the child is presented first with a social risk (an increasingly intrusive male stranger), then with a physical risk (a set of stairs), and then forbidden by the parent to climb the stairs. In the SS as conceived by Mary Ainsworth, the child's stress is gradually increased in order to trigger the attachment system; the ultimate objective is for the child to find a balance between exploring the environment and seeking comfort from the significant parent [20]. In the RS, the child is invited to take progressive risks in order to trigger the activation system, ideally a balance between exploration of the environment and acceptance by the child of limits imposed by the significant parent. In the SS, the way the child reacts when the parent returns determines the quality of the attachment relationship. Secure children (type B) welcome their parents, are comforted by them, and return to their exploration of the toys in the room. Avoidant children (type A) experience distress but do not show it and do not try to obtain the comfort they need. They continue their exploration but are less engaged than before. Resistant children (type $\mathrm{C}$ ) are harder to comfort and stop or significantly reduce their exploration. Disorganized children (type D) act in a strange and contradictory way, both desiring comfort and rejecting it at the same time, while also exploring in a disoriented manner [21]. The scoring grid used to code the RS identifies children with underactivated relationships, activated relationships, and overactivated relationships. Underactivated children engage in little exploration, are passive and withdraw from novelty, or remain close to their parents. Activated children are confident and prudent in their exploration and conform when their parents set limits. Overactivated children are reckless and do not comply when their parents set limits. The underactivated relationship is theoretically linked to parental overprotection, while the overactivated relationship is linked to parental difficulty in applying discipline (for the child's protection). Paquette and Bigras [18] have shown that the threefold attachment typology $(\mathrm{ABC})$ using the SS and the activation typology using the RS are orthogonal and evaluate different constructs. On the other hand, they have also highlighted the link between the activation typology and the attachment disorganization score. The literature demonstrates that it is primarily children with disorganized attachment who develop psychopathology $[22,23]$.

Depending on whether conditions in the environment are favorable, based on resource availability and the presence of potential dangers, parents would be expected to activate their children to varying degrees, preparing them for intrasex competition and to cope with adversity [16]. The activation relationship theory predicts that fathers will activate children more than mothers, and boys will be activated more than girls [18]. According to Charlesworth's evolutionist model [24], competition for limited resources may be manifested in five categories of behavior: aggression, intimidation, manipulation, deceit, and cooperation.

The activation relationship being theoretically linked to risk taking in competition for environmental resources at all ages, one might expect to find a sex difference in the prevalence of activation types early on, beginning in toddlerhood, before the appearance of sex differences in competition strategies such as aggression. Physical aggression appears in young children at an early age, around 8 or 9 months, and for the vast majority peaks at between 15 and 24 months [25]. The age of two years also corresponds to a period during which children assert their autonomy, which manifests itself through increased opposition towards adults. It is also the age at which children establish a dominance hierarchy amongst themselves. But it is only at about age three that boys engage in significantly more physical aggression and become more focused on dominance than girls [26], in Western industrial societies at least. One might conclude that the form of risk taking that constitutes aggression is modulated by the activation relationship to increase or decrease sex differences in aggression depending on whether it occurs in a society that is individualistic or collectivist. In individualistic societies, aggression would be encouraged by parents, while in collectivist societies aggression between children would be discouraged.

Using a combined sample of 21 father-child dyads and 21 mother-child dyads, Paquette and Bigras [18] have found that (1) the parent-child activation relationship is linked to parental stimulation of risk taking after controlling for child characteristics (sex, temperament) and that (2) avoidant children (as assessed with the SS) and overactivated children (as assessed with the RS) have higher disorganized attachment scores than secure children and under-activated children, respectively. This final result suggests that disorganization is tied to children experiencing an extreme lack of protection in their environment given that avoidant children tolerate being at a greater distance from the parent, and overactivated children explore their environment impulsively and recklessly. In 
addition, using a sample of 21 father-child dyads, Paquette and Bigras [18] demonstrated that boys are more activated than girls in toddlerhood, even though no sex differences were found in the father-child attachment relationship. However, they did not obtain a significant sex difference for the activation relationship with a second sample of 21 fatherchild dyads. The purpose of the current study was therefore to confirm, with a larger sample solely comprised of fathers, that the activation relationship is primarily determined by parental stimulation of risk taking after controlling for child characteristics. The second objective was to verify the link between the activation relationship and attachment disorganization. Given the instability of results for sex differences in small samples, the third objective here was to replicate the study with a larger sample to verify the existence of sex differences in the father-child activation relationship. The concept of the activation relationship would only be relevant to our understanding of the parent-child relationship, and the father-child relationship in particular, if a certain degree of stability could successfully be demonstrated in the expected results.

\section{Method}

2.1. Participants. The sample was comprised of 58 fatherchild dyads with 22 boys and 36 girls. It should be noted that the first 21 dyads recruited for this sample were used for the validation of the Risky Situation [18]. Four children (3 girls and 1 boy) were eliminated from the sample, one due to low motor skills development and the other three because their fathers were unable to comfort them when they cried during the RS.

The average age for fathers was 34.8 years (ranging between 25 and 49 years; $\mathrm{SD}=5.16)$. The average number of children per family was 1.7 (ranging between 1 and 5; SD = .89 ) and $5.2 \%$ of the sample were single parents. Seventynine percent (79\%) of fathers were born in North America. The average number of years of schooling was 15.4 years (ranging between 9 and 23; SD $=2.59$ ) and $41 \%$ of the sample had an annual family income greater than CAN $\$ 80.000$. Finally, fathers spent an average of 40.5 hours a week working (ranging between 20 and 80; SD $=10.55$ ) and 13.2 hours a week alone with their child (ranging between 0 and 69; $\mathrm{SD}=14.22$ ).

2.2. Procedure. Fathers were recruited through monthly ads in several neighborhood newspapers and early childhood centers in the city of Montreal. Fathers were then contacted by phone to set up a first appointment at the University of Montreal. The two procedures (SS and RS) were conducted at one-month intervals in a counterbalanced manner (i.e., the RS was done first in half the cases). After having the father sign a consent form, a team of student assistants (2-3) made a video recording of one of the two observational procedures. The father then completed questionnaires while an assistant played with the child in the same room. The same sequence was followed at the second appointment. The procedures (SS and RS) were conducted in two different rooms, each equipped with three hidden cameras. The average age of children at the time of the RS was 15.8 months (ranging between 12.0 and 19.2; $\mathrm{SD}=2.14$ ). The average age of children at the time of the SS was 15.8 months (ranging between 12.4 and 19.4; $\mathrm{SD}=1.92$ ). No attrition occurred between the two time points. Fathers received \$20CAN per session.

\subsection{Instruments}

2.3.1. The Strange Situation Procedure (SS [19]). The SS is a standardized procedure designed to assess the quality of the parent-child attachment relationship in children ages 12 to 18 months. The SS is divided into eight episodes and takes place in an unfamiliar room with toys. During the procedure, infants are exposed to mildly stressful events, including the entrance of an unfamiliar female adult and two separations from their parent followed by reunions. Infant attachment patterns are coded by trained observers and classified as secure (B), insecure avoidant (A), or insecure resistant (C), based on the Ainsworth et al. [19] scoring system. In this procedure, children must cope with the considerable distress of having their parent leave them alone for two minutes in an unfamiliar room with a complete stranger. The way the child reacts when the parent returns determines the quality of their attachment relationship. Then the Main and Solomon's [21] scoring system is used to code disorganized attachment (D). Disorganized children act in a strange and contradictory way, both desiring comfort and rejecting it at the same time, while also exploring in a disoriented manner. This system produces a disorganization score from 1 to 9 , with the score of 5 being the cut-off point for the D category. Twenty-six percent $(15 / 58)$ of the children in our sample were placed in the $\mathrm{D}$ category. Seventeen percent of the sample was coded by a second rater. Interrater agreement (Kappa) for the threeand the four-category scheme was $76 \%$. Finally, an intraclass correlation of .73 was obtained for the disorganization scale.

2.3.2. The Risky Situation Procedure (RS [18]). The RS is a standardized procedure designed to assess the quality of the parent-child activation relationship in children ages 12 to 18 months [18]. The activation relationship theory serves as a complement to Bowlby's attachment theory to better understand the impact of fathering on child development. According to the activation relationship theory, children's feelings of confidence result from parental encouragement of risk taking during children's exploration of their environment, with parents protecting their children through discipline (limit setting, control).

The procedure lasts about 20 minutes and takes place in an unfamiliar room. It is divided into six structured episodes lasting three minutes each. After instructions have been given to the parent, the child is seated on the floor in front of available toys, while the parent reads a magazine on a chair behind the child (Episode 1). Then, a male stranger enters the room, sits on the floor, and starts playing with the toys without interacting with the child or the parent (Episode 2). After three minutes, or earlier, if the child initiates interaction with him, the male stranger starts playing with the child and becomes increasingly stimulating and intrusive (Episode 3). Toys are put away and a big colorful set of stairs that was 
hidden behind drapes is revealed (Episode 4); the parent is instructed to get up from the chair to make sure the child is safe during exploration only if the latter starts to climb the stairs. The parent is then asked to encourage the child to go up and down the stairs (Episode 5). Finally, the parent is asked to forbid the child to climb the stairs (Episode 6). Throughout the procedure, the parent is allowed to interact with the child when discipline is required, when giving instructions to stimulate the child, or when comfort is needed by the child; otherwise the child is to be left alone, for the same reason as in the SS. The coding grid permits children to be classified as activated, underactivated, or overactivated and also provides an activation score between 0 and 5 indicating the extent to which the child is optimally activated (with the score of 5 corresponding to the most positive activation relationship). In the RS, underactivated children tend to engage in little exploration, be passive, and withdraw from novelty or remain close to the parent. Activated children are confident and prudent in their exploration and obey when the parent sets a limit. Overactivated children are reckless and noncompliant when the parent sets limits. The coding system with its five criteria was designed for ease of use by clinicians as well as researchers, requiring an average of 30 minutes per case.

Interrater agreement (Kappa) was $70 \%$ for classification of the three types and $82 \%$ for decisions based on the five criteria. Intraclass correlation was $.93(P<.001)$ for the activation score. All cases (100\% of the sample) were then discussed until a consensus could be reached by the two authors.

2.3.3. Child Temperament. Child temperament was assessed using the French version of the Early Childhood Behavior Questionnaire [27]. The following six scales were selected as they are theoretically closer to the concept of activation: Frustration ( 8 items; $\alpha=.75$ ); Shyness (12 items; $\alpha=.77$ ); Fear (7 items; $\alpha=.74)$; Impulsivity (5 items; $\alpha=.77$ ); Inhibitory control (12 items; $\alpha=.81$ ); and Sociability ( 8 items; $\alpha=.89$ ). Four (4) items, 4 items, and 5 items were removed from the frustration, fear, and impulsivity scales, respectively, to obtain alphas greater than .70 .

2.3.4. Parental Behavior. Parental behavior was assessed with self-report questionnaires. The Openness to the World Questionnaire (OWQ: [28]), based on the activation relationship theory, was used to assess three dimensions in the toddler period and the preschool period. Although validated with a sample of preschool children (ages 26 to 69 months), it was also used with toddlers in the current study. Stimulation of perseverance consists of encouraging the child to accomplish difficult things, overcome personal limits, and persevere in the face of adversity, introducing the child to sports and inviting the child to explore or initiate contact with an unfamiliar child: this scale has an internal consistency of .61 (7 items) for the toddler period and is significantly correlated to the same scale for the preschool period $(r=.37, P<.01, n=$ 48). Punishment consists of punishing or scolding the child if the child disobeys, does not try, or breaks something: this scale has an internal consistency of .61 (6 items) for the toddler period and is significantly correlated to the same scale for the preschool period ( $r=.37, P<.01, n=48)$. Finally, stimulation of risk taking consists of encouraging the child to undertake risky activities and allowing the child substantial autonomy in the child's exploration of the environment: this scale has an internal consistency of .65 (7 items) and is significantly correlated to the same scale for the preschool period $(r=.67, P<.001, n=48)$.

In order to replicate Paquette and Bigras' (2010) study, we used the same two scales from the Montreal Father's Involvement Questionnaire (MFIQ: [29]). Internal consistency estimates for the current study are good. Basic care (8 items; $\alpha=.76$ ) comprises items such as bathing, dressing, feeding, and nursing the child. Emotional support (12 items; $\alpha=.82$ ) comprises parental behaviors that clearly communicate to the child that he or she is appreciated, loved, supported, and protected.

\section{Results}

In the results section, we will first verify whether there are sex differences in the scores for the child temperament and fathers' parental behavior scales. Next, we will verify the presence of sex differences in the prevalence of types of attachment and activation. We will then verify links between temperament, parental behavior, and attachment disorganization, first using the threefold typology of attachment and then the activation relationship typology. Finally, to verify whether parental stimulation of risk taking explains the father-child activation relationship after extracting the effects of other variables, we will conduct a hierarchical regression of the activation score by first entering child's sex; followed by child temperament, father-child attachment, and emotional support; and finally stimulation of risk taking.

\subsection{Sex Differences in Child Temperament and Fathers' Paren-} tal Behavior. No dimension of temperament was shown to differ by child's sex. In addition, the average scores for parental stimulation of risk taking, stimulation of perseverance, and punishment were not significantly different for girls and boys. However, girls received significantly more emotional support from their fathers than boys $(t=2.88, d f=$ $1, P<.01)$. Girls also received more basic care than boys, but the difference was not significant $(t=1.73, d f=1, P=.09)$.

3.2. Sex Differences in the Prevalence of Activation Types and Attachment Types. Table 1 shows that $24.1 \%$ of children were both secure and activated with their fathers, indicating that children who were confident would be comforted in times of distress and protected by limit setting during their exploration of environments in which danger was present. Two groups came second in terms of size. Children who were both secure and underactivated were children who were adequately comforted in times of distress but received little encouragement to explore their environment by themselves without the parent (18.5\%). Children who were both secure and overactivated were children who were comforted and soothed in times of distress but received little discipline $(20.4 \%)$. Last came the children who were both avoidant and 
TABle 1: Percentage $(n)$ of dyads as a function of three strange situation categories $(\mathrm{A}, \mathrm{B}, \mathrm{C})$ and risky situation categories.

\begin{tabular}{lcccc}
\hline Risky situation & $\mathrm{A}$ & $\mathrm{B}$ & $\mathrm{C}$ & $\begin{array}{c}\text { Total } \\
\text { (boys; girls) }\end{array}$ \\
\hline Underactivated & $1.9 \%$ & $18.5 \%$ & $5.6 \%$ & $25.9 \%$ \\
& $(1)$ & $(10)$ & $(3)$ & $(1 ; 13)$ \\
Activated & $14.8 \%$ & $24.1 \%$ & $3.7 \%$ & $42.6 \%$ \\
& $(8)$ & $(13)$ & $(2)$ & $(13 ; 10)$ \\
Overactivated & $9.3 \%$ & $20.4 \%$ & $1.9 \%$ & $31.5 \%$ \\
& $(5)$ & $(11)$ & $(1)$ & $(7,10)$ \\
Total & $25.9 \%$ & $63.0 \%$ & $11.1 \%$ & $100.0 \%$ \\
(boys; girls) & $(6 ; 8)$ & $(15 ; 19)$ & $(0 ; 6)$ & $(54)$ \\
\hline
\end{tabular}

TABle 2: Percentage $(n)$ of dyads as a function of four strange situation categories $(A, B, C, D)$ and risky situation categories.

\begin{tabular}{lccccc}
\hline Risky situation & $\mathrm{A}$ & $\mathrm{B}$ & $\mathrm{C}$ & $\mathrm{D}$ & $\begin{array}{c}\text { Total } \\
\text { (boys; girls) }\end{array}$ \\
\hline Under-activated & $0 \%$ & $18.5 \%$ & $3.7 \%$ & $3.7 \%$ & $25.9 \%$ \\
& $(0)$ & $(10)$ & $(2)$ & $(2)$ & $(1 ; 13)$ \\
Activated & $5.6 \%$ & $22.2 \%$ & $1.9 \%$ & $13.0 \%$ & $42.6 \%$ \\
& $(3)$ & $(12)$ & $(1)$ & $(7)$ & $(13 ; 10)$ \\
Over-activated & $3.7 \%$ & $18.5 \%$ & $1.9 \%$ & $7.4 \%$ & $31.5 \%$ \\
Total & $(2)$ & $(10)$ & $(1)$ & $(4)$ & $(7 ; 10)$ \\
(boys; girls) & $9.3 \%$ & $59.2 \%$ & $7.5 \%$ & $24.1 \%$ & $100.0 \%$ \\
\hline
\end{tabular}

activated (14.8\%), meaning children who seemed independent of the parent in times of distress but who would accept limits imposed by the latter during exploration.

Of the children in the sample, $63.0 \%$ were secure children, $25.9 \%$ avoidant children, and $11.1 \%$ resistant children (Table 1). As in the literature, chi-square analyses showed that attachment type prevalence did not differ based on the child's $\operatorname{sex}\left(\chi^{2}=4.30, d f=2, P>.05\right)$.

Forty-three percent $(42.6 \%)$ of children in the sample were activated, $25.9 \%$ were underactivated, and $31.5 \%$ were overactivated (Table 1). Chi-square analysis showed that activation prevalence differed based on the child's sex $\left(\chi^{2}=\right.$ 8.98, $d f=2, P<.05): 93 \%$ of underactivated children were girls. Moreover, the average activation score for boys as a group (3.29) was significantly higher than that (2.48) of girls $(t(1,52)=-2.54, P<.05)$.

With respect to the fourfold typology of attachment, the results revealed that $24.1 \%$ of children displayed disorganized attachment with their father (Table 2).

\subsection{Relation of Child Temperament, Parental Behavior, and Attachment Disorganization to Father-Child Relationships}

3.3.1. Attachment Relationship. Only one dimension of temperament varied significantly among the three attachment categories $(\mathrm{ABC})$ : sociability $(F(2,45)=3.73, P<.05)$. Scheffe tests showed that the sociability score for avoidant children was higher than the score for resistant children $(P<$ $.05)$, while the score for secure children did not differ from that for avoidant children but showed a trend toward being higher than the score for resistant children $(P=.07)$. There were no significant differences in basic care and emotional support for the three categories of attachment. However, stimulation of risk taking differed significantly among the three categories $(F(2,45)=4.22, P<.05)$ : Scheffe tests showed that fathers of resistant children stimulated risk taking less than fathers of secure children $(P<.01)$ and fathers of avoidant children $(P<.01)$. It should be noted that fathers did as much risk taking stimulation with secure children as with avoidant children. On the other hand, stimulation of risk taking was not significantly different for the four categories of attachment $(F(3,50)=1.76, P>.05)$.

One-way ANOVA analysis revealed significant differences among the three attachment types (ABC) for the attachment disorganization score $(F(2,51)=13.28, P<.001)$; Scheffe tests showed the average score of avoidant children (5.3) to be higher than that of secure children (2.2) $(P<$ .001 ), with the average score of resistant children (3.8) being between the scores of avoidant children and secure children.

3.3.2. Activation Relationship. One-way analysis showed no significant difference among the three types of activation relationships for any temperament scales other than frustration $(F(2,51)=4.08, P<.01)$ : activated children had higher frustration scores than both under- and overactivated children, but the difference was only significant with regard to overactivated children (Scheffe, $P<.05$ ). There was no significant correlation between the activation score and temperament scales for the sample as a whole. However, there was a significant positive correlation between frustration and activation in girls only ( $r=.37, P<.05 ; r=-.13$ in boys).

The average stimulation of risk taking scores for activated children and overactivated children was similar, and both were higher than the average score for underactivated children although the difference was not significant. The activation score showed a trend toward being significantly correlated with stimulation of risk taking $(r=.23, P=$ .09 ) and was significantly correlated with emotional support $(r=-.29, P=.05)$. It should be noted that the correlation between activation score and emotional support remained significant for boys only ( $r=-.49, P<.05 ; r=.02$ for girls).

One-way ANOVA analysis revealed no significant differences among the three activation types for the attachment disorganization score $(F(2,51)=.93, P>.05)$.

3.4. Effect of Parental Stimulation of Risk Taking after Controlling for Child's Sex and Temperament, Father-Child Attachment, and Emotional Support. Multiple regressions were conducted to verify whether paternal stimulation of risk taking explained activation once child sex and temperament, attachment relationship, and emotional support were taken into account. Multiple regression analysis was performed by first forcing child sex, then entering frustration, attachment ( $C$ versus $A B)$, and emotional support, and finally entering stimulation of risk taking stepwise. This model explains $26 \%$ of total variance (Table 3 ) and confirms the importance of paternal stimulation of risk taking in the father-child activation relationship. 
TABLE 3: Multiple regression on the activation score $(n=54)$.

\begin{tabular}{lccccc}
\hline Variables & $R^{2}$ & $F$ change & $\beta$ & $t$ & $P$ \\
\hline Step 1 & .110 & $6.43^{*}$ & & & \\
$\quad$ Child's sex & & & -.33 & -2.54 & .014 \\
Step 2 & .188 & 1.56 & & & \\
$\quad$ Child's sex & & & -.23 & -1.56 & .126 \\
$\quad$ Frustration & & & .22 & 1.64 & .107 \\
$\quad$ Attachment & & & .06 & .41 & .686 \\
$\quad$ Emotional support & & & -.24 & -1.68 & .100 \\
Step 3 & .260 & $4.65^{*}$ & & & \\
Child's sex & & & -.26 & -1.87 & .068 \\
Frustration & & & .25 & 1.90 & .063 \\
$\quad$ Attachment & & & .22 & 1.41 & .165 \\
Emotional support & & & -.23 & -1.68 & .099 \\
Risk stimulation & & & .31 & 2.16 & .036 \\
\hline${ }^{*} P<.05$. & & & & &
\end{tabular}

\section{Discussion}

This study confirms that the attachment and activation relationships are two different mechanisms. It demonstrates the independence of the attachment relationship (as measured with the Strange Situation) and the activation relationship (as measured with the Risky Situation) as only $24 \%$ of children were both secure and activated with the father. Analyses with this larger sample also confirm the presence of sex differences in the activation relationship as early as toddlerhood: boys are activated more by their fathers than girls are, and this result is just as evident with respect to classification as to the activation score. Furthermore, as has been found for mother-child attachment [30], there is no sex difference in father-child attachment. The study also confirms that paternal stimulation of risk taking explains the activation score not only after controlling for child characteristics but also after controlling for father-child attachment and emotional support. Finally, we found no association between the activation relationship and attachment disorganization in this sample of father-child dyads $(n=54)$ even though Paquette and Bigras [18] found such an association in an equal mix sample of father-child and mother-child dyads $(n=42)$. Frightening behaviors from the primary caregiver have been associated with the development of disorganized attachment in children [31]. Hazen et al. [32] have shown frightening behaviors by mothers to be more problematic for child outcomes than frightening behaviors by fathers; when combined with sensitivity, such behaviors in fathers serve to surprise and destabilize children, thereby encouraging them to explore their environment.

Contrary to the first two samples in Paquette and Bigras's [18] study, the current larger sample shows no connection between the activation relationship and dimensions of temperament such as impulsivity, shyness, and sociability. Moreover, we obtained no sex difference for the six dimensions of temperament as assessed by the father. Although sex differences have been reported primarily in older children and adults in the literature, self-report questionnaires have also revealed sex differences in infancy and toddlerhood for different dimensions of temperament. Some studies have shown more shyness, fear, and withdrawal in girls and greater interest in approaching novel objects, more high-intensity pleasure, and a higher level of activity in boys [27, 33, 34]. Other studies have found more effortful control (inhibitory control and perceptual sensitivity) and sociability in girls and more impulsivity in boys [33]. Indeed, sex differences in temperament may emerge at different ages and decrease or increase over the course of development depending on maturation and socialization processes [33].

On the other hand, the current study reveals a connection between frustration and the activation relationship: activated children had higher father-rated frustration scores than overactivated children. It could be that fathers provoke more frustration in activated children by setting limits while fathers of overactivated children are more permissive. But given the significant positive correlation between frustration scores and activation only in girls, who made up the better part of the sample, it is believed that this result mainly reflects the fact that girls have a greater tendency than boys to express their frustration with limits and risk taking.

The fact that there is an early sex difference in the father-child relationship, at an age at which sex differences in temperament are difficult to detect, would seem to support the hypothesis that the father plays a unique role in amplifying or reducing children's innate tendencies, depending on the environment. It is possible that differential gender socialization, generally more pronounced in fathers [35], occurs through the activation relationship mechanism. Through the activation relationship, the father would adjust stimulation of risk taking and limit setting based on the child's temperament to encourage the child to explore the physical and social environment autonomously and carefully. Risk taking is a basic need, permitting children to explore their environment, develop skills, and therefore adapt. Children's temperaments would seem to predispose them to take more or less risks, but they need their parents to learn how to regulate their behavior. For example, parents must encourage inhibited children to explore more, but must exercise more control over impulsive children. Men, who generally take more risks than women [36], are perhaps more predisposed on average to encouraging this type of learning, provided of course that they themselves have learned to regulate their own risk taking. Jaffee et al. [37] have shown antisociality in fathers (but not mothers) to be a predictor of behavior problems in offspring, even after controlling for genetic factors. The sensation seeking and risk taking in extreme sports observed in a number of adolescents may be the result of such learning not having taken place at an early age, due to either overprotective or overly permissive parents.

To explore why fathers engage more frequently in roughand-tumble play (RTP) with boys than with girls, Paquette and Dumont [38] tested the association of RTP with fatherchild attachment (as assessed with the Strange Situation) and with father-child activation (as assessed with the Risky Situation) and showed that the more optimally activated boys are by their fathers in toddlerhood, the more RTP the boys engage in with their fathers at the age of three years. RTP is a proximate mechanism that has been theorized to contribute 
to the development of the father-child activation relationship in preschoolers and to encourage the development of competition skills including aggression [16]. Flanders et al. [39, 40] have shown that the association between the frequency of father-child RTP in the preschool period and the frequency of physical aggression (as evaluated through self-report questionnaires) is moderated by the father's dominance during RTP, that is to say the degree to which the father controls the flow of play or holds the dominant position (evaluated through observation). When fathers are not dominant over their children, RTP frequency is greater, children are more physically aggressive, and have less emotion regulation five years later $[39,40]$.

What is more surprising is that fathers do not make a greater attempt to stimulate risk taking in boys than in girls. However, they do provide more emotional support and basic care to girls than to boys. Also, the lower the degree of emotional support and basic care provided by the father, the higher the boy's activation score. Paquette and Bigras [18] have suggested that low basic care combined with stimulation of risk taking may promote activation more than stimulation of risk taking alone. The higher proportion of girls in the current sample may also have affected averages.

It is worth taking a closer look at some of the results regarding the father-child attachment relationship. First, as in Paquette and Bigras' [18] study with fathers and mothers, the current sample reveals no significant difference with respect to basic care and emotional support by fathers for the three types of attachment. However, two results do differ. On the one hand, the average sociability score for avoidant children is not significantly different from the score for secure children, while both are higher than the average score for resistant children. This result is just as surprising as that of Youngblade et al. [3] who have demonstrated that children with insecure attachment to their fathers have more positive interactions with their peers. In our opinion, the attachment relationship reflected by the Strange Situation procedure is more meaningful when the father is the child's principal caregiver and comfort provider on a daily basis, which of course represents a minority in the general population. In other words, this result supports the notion that the Strange Situation evaluates something different when used with father-child dyads. If such is the case, it would be important not to interpret the abnormally high level of disorganized attachment (24\%) in our sample of father-child dyads as an indication of the presence of adjustment issues. Our results show disorganized attachment to be combined with avoidant attachment in $69.2 \%$ of cases, a combination found in only $34 \%$ of children in middle-class, nonclinical groups [41]. However, according to a meta-analysis by Van Ijzendoorn et al. [41], resistant children have the most significant association with disorganization (46\% of cases of disorganization). Given that Van Ijzendoorn's study provides data on parents that does not distinguish between fathers and mothers, it is impossible to know whether the strong association between avoidance and disorganization is typical of the father-child attachment relationship. On the other hand, the average stimulation of risk taking score is linked to attachment classification: the average stimulation of risk taking score for avoidant children is not significantly different from the average score for secure children, but both are higher than the average score for resistant children. This could mean that resistant children elicit more restrictive and overprotective behavior in their fathers. But it could also mean that fathers activate their children even when they are acting as a secure base, comforting children when the latter are tired, hungry, sick, afraid, or feeling insecure in the presence of novelty. Indeed, it is entirely possible that fathers activate children through the different way in which they carry out the same caretaking tasks (bottle feeding, changing diapers, etc.) especially when they are the secondary attachment figure and primary activation figure. Despite this association between attachment and the stimulation of risk taking, we have been able to show that paternal stimulation of risk taking explains the activation score after controlling for the father-child attachment relationship.

It is important to point out that the results obtained may be related to the study's limitations. The first limitation is that our sample is not representative of the general population. As recruitment was conducted via newspapers and early childhood centers in the city of Montreal, the fathers who responded to our advertisement would be, on average, more affluent and also probably those fathers who consider themselves to be most involved with their children. In spite of this, we obtained sufficient numbers of cases of each of the three types of activation relationships to conduct analyses. In addition, our sample contained a greater number of girls than of boys. Furthermore, child temperament and parental behavior were assessed solely using self-report questionnaires completed by the father rather than through triangulation of the information with the mother's perception. Finally, the internal consistency (alpha) of the model's central variable, the stimulation of risk taking, was acceptable but weak.

A study with a sample comprised entirely of mother-child dyads might perhaps reveal that it is in fact the activation relationship itself that plays this role, independent of the sex of the person who fulfills the paternal function of opening the child up to the outside world. It would be important now to demonstrate that the activation relationship and the attachment relationship are indeed complementary mechanisms fostering different developmental outcomes in children. It is therefore vital that future studies evaluate these two types of relationships with the mother and the father within the family system to accurately predict the socioaffective development of children to adulthood. The activation relationship theory should predict competition and risk taking in children including aggression. Our results show that sex differences in the father-child activation relationship appear prior to the sex difference in physical aggression that generally appears at about three years of age [26]. However, it will be necessary to demonstrate in future longitudinal studies that the fatherchild activation relationship predicts the frequency of physical aggression and risk taking in preschool-age boys while the father-child attachment relationship does not. Indeed, to date, problems of aggression have been linked more to disorganization [22] than to the $\mathrm{ABC}$ types of attachment $[23,42]$. The prediction has been made that overactivated children will have a greater tendency to develop externalizing 
problems while underactivated children will have a greater tendency to develop internalizing problems [18].

\section{Acknowledgment}

Researchers thank Dr. Jacinthe Emery for coding the Strange Situation.

\section{References}

[1] G. J. Suess, K. E. Grossmann, and L. A. Sroufe, "Effects of infant attachment to mother and father on quality of adaptation in preschool: from dyadic to individual organization of self," International Journal of Behavioral Development, vol. 15, pp. 4365, 1992.

[2] M. H. Van Ijzendoorn, "Adult attachment representations, parental responsiveness, and infant attachment: a meta-analysis on the predictive validity of the adult attachment interview," Psychological Bulletin, vol. 117, no. 3, pp. 387-403, 1995.

[3] L. M. Youngblade, K. A. Park, and J. Belsky, "Measurement of young children's close friendship: a comparison of 2 independent assessment systems and their associations with attachment security," International Journal of Behavioral Development, vol. 16, pp. 563-587, 1993.

[4] K. E. Grossmann and K. Grossmann, "Développement de lattachement et adaptation psychologique du berceau au tombeau," Enfance, vol. 3, pp. 3-12, 1998.

[5] K. Grossmann, K. E. Grossmann, H. Kindler, and P. Zimmermann, "A wider view of attachment and exploration: the influence of mothers and fathers on the development of psychological security from infancy to young adulthood," in Handbook of Attachment, Theory, Research, and Clinical Applications, J. Cassidy and P. R. Shaver, Eds., pp. 857-879, Guildford Press, New York, NY, USA, 2nd edition, 2008.

[6] I. Bretherton, "Fathers in attachment theory and research: a review," Early Child Development and Care, vol. 180, no. 1-2, pp. 9-23, 2010.

[7] C. Dumont and D. Paquette, "Lattachement père-enfant et l'engagement paternel: deux concepts centraux pour mieux prédire le développement de l'enfant," Revue de Psychoéducation, vol. 37, no. 1, pp. 27-46, 2008.

[8] K. Kazura, "Father's qualitative and quantitative involvement: an investigation of attachment, play, and social interactions," The Journal of Men's Studies, vol. 9, no. 1, pp. 41-57, 2000.

[9] L. A. Newland and D. D. Coyl, "Fathers' role as attachment figures: an interview with Sir Richard Bowlby," Early Child Development and Care, vol. 180, no. 1-2, pp. 25-32, 2010.

[10] O. N. Saracho and B. Spodek, "Father's: the "invisible" parents," Early Child Development and Care, vol. 178, no. 7-8, pp. 821-836, 2008.

[11] S. D. Dixon, M. Yogman, and E. Tronick, "Early infant social interaction with parents and strangers," Journal of the American Academy of Child Psychiatry, vol. 20, no. 1, pp. 32-52, 1981.

[12] K. MacDonald and R. D. Parke, "Parent-child physical play: the effects of sex and age of children and parents," Sex Roles, vol. 15, no. 7-8, pp. 367-378, 1986.

[13] F. Labrell, "Paternal play with toddlers: recreation and creation," European Journal of Psychology of Education, vol. 11, no. 1, pp. 43-54, 1996.

[14] S. Kromelow, C. Harding, and M. Touris, "The role of the father in the development of stranger sociability during the second year," American Journal of Orthopsychiatry, vol. 60, no. 4, pp. 521-530, 1990.

[15] K. Grossmann, K. E. Grossmann, E. Fremmer-Bombik, H. Kindler, H. Scheuerer-Englisch, and P. Zimmermann, "The uniqueness of the child-father attachment relationship: fathers' sensitive and challenging play as a pivotal variable in a 16-year longitudinal study," Social Development, vol. 11, no. 3, pp. 307331, 2002.

[16] D. Paquette, "Theorizing the father-child relationship: mechanisms and developmental outcomes," Human Development, vol. 47, no. 4, pp. 193-219, 2004.

[17] D. Paquette, "La relation père-enfant et l'ouverture au monde," Enfance, vol. 2, pp. 205-225, 2004.

[18] D. Paquette and M. Bigras, “The risky situation: a procedure for assessing the father-child activation relationship," Early Child Development and Care, vol. 180, no. 1-2, pp. 33-50, 2010.

[19] M. D. S. Ainsworth, M. C. Blehar, E. Waters, and S. Wall, Patterns of Attachment: A Psychological Study of the Strange Situation, Lawrence Erlbaum, Hillsdale, NJ, USA, 1978.

[20] G. Cooper, K. Hoffman, B. Powell, and R. Marvin, "The circle of security intervention," in Enhancing Early Attachments: Theory, Research, Intervention, and Policy, L. J. Berlin, Y. Ziv, L. M. Amaya-Jackson, and M. T. Greenberg, Eds., Guilford Press, New York, NY, USA, 2005.

[21] M. Main and J. Solomon, "Procedure for identifying infants as disorganized/disoriented during the Ainsworth strange situation," in Attachment in the Preschool Years: Theory, Research and Intervention, M. T. Greenberg, D. Cicchetti, and E. M. Cummings, Eds., pp. 121-160, University of Chicago Press, Chicago, Ill, USA, 1990.

[22] K. Lyons-Ruth and D. Jacobvitz, "Attachment disorganization: genetic factors, parenting contexts, and developmental transformation from infancy to adulthood," in Handbook of Attachment: Theory, Research, and Clinical Applications, J. Cassidy and P. R. Shaver, Eds., pp. 666-697, Guilford Press, London, UK, 2nd edition, 2008.

[23] M. DeKlyen and M. T. Greenberg, "Attachment and psychopathology in childhood," in Handbook of Attachment: Theory, Research, and Clinical Applications, J. Cassidy and P. R. Shaver, Eds., pp. 637-665, Guilford Press, New York, NY, USA, 2nd edition, 2008.

[24] W. R. Charlesworth, "Resources and resource acquisition during ontogeny," in Sociobiological Perspective on Human Development, K. B. MacDonald, Ed., pp. 24-77, Springer, New York, NY, USA, 1988.

[25] R. E. Tremblay, C. Japel, D. Perusse et al., "The search for the age of "onset" of physical aggression: Rousseau and Bandura revisited," Criminal Behaviour and Mental Health, vol. 9, no. 1, pp. 8-23, 1999.

[26] J. Archer and S. Côté, "Sex differences in aggressive behaviour: a developmental and evolutionary perspective," in Developmental Origins of Aggression, R. E. Tremblay, W. W. Hartup, and J. Archer, Eds., pp. 425-443, Guilford Press, London, UK, 2005.

[27] S. P. Putnam, M. A. Gartstein, and M. K. Rothbart, "Measurement of fine-grained aspects of toddler temperament. The Early Childhood Behavior Questionnaire," Infant Behavior and Development, vol. 29, no. 3, pp. 386-401, 2006.

[28] D. Paquette, M. M. Eugène, D. Dubeau, and M.-N. Gagnon, "Les pères ont-ils une influence spécifique sur le développement des enfants?" in La Paternité Au 21e Siècle, D. Dubeau, A. Devault, and G. Forget, Eds., pp. 99-122, PUL, Québec, Canada, 2009. 
[29] D. Paquette, C. Bolté, G. Turcotte, D. Dubeau, and C. Bouchard, "A new typology of fathering: defining and associated variables," Infant and Child Development, vol. 9, no. 4, pp. 213-230, 2000.

[30] M. H. Van Ijzendoorn, G. Moran, J. Belsky, D. Pederson, M. J. Bakermans-Kranenburg, and K. Kneppers, "The similarity of siblings' attachments to their mother," Child Development, vol. 71, no. 4, pp. 1086-1098, 2000.

[31] M. Main and E. Hesse, "Parents unresolved traumatic experiences are related to infant disorganized attachment status: is frightened and/or frightening parental behavior the linking mechanism?" in Attachment in the Preschool Years: Theory, Research and Intervention, M. T. Greenberg, D. Cicchetti, and E. M. Cummings, Eds., pp. 161-182, University of Chicago Press, Chicago, Ill, USA, 1990.

[32] N. L. Hazen, L. McFarland, D. Jacobvitz, and E. Boyd-Soisson, "Fathers' frightening behaviours and sensitivity with infants: relations with fathers' attachment representations, father-infant attachment, and children's later outcomes," Early Child Development and Care, vol. 180, no. 1-2, pp. 51-69, 2010.

[33] N. M. Else-Quest, J. S. Hyde, H. H. Goldsmith, and C. A. Van Hulle, "Gender differences in temperament: a meta-analysis," Psychological Bulletin, vol. 132, no. 1, pp. 33-72, 2006.

[34] M. A. Gartstein and M. K. Rothbart, "Studying infant temperament via the Revised Infant Behavior Questionnaire," Infant Behavior and Development, vol. 26, no. 1, pp. 64-86, 2003.

[35] H. Lytton and D. M. Romney, "Parents' differential socialization of boys and girls: a meta-analysis," Psychological Bulletin, vol. 109, no. 2, pp. 267-296, 1991.

[36] J. P. Byrnes, D. C. Miller, and W. D. Schafer, "Gender differences in risk taking: a meta-analysis," Psychological Bulletin, vol. 125, no. 3, pp. 367-383, 1999.

[37] S. R. Jaffee, T. E. Moffitt, A. Caspi, and A. Taylor, "Life with (without) father: the benefits of living with two biological parents depend on the father's antisocial behavior," Child Development, vol. 74, no. 1, pp. 109-126, 2003.

[38] D. Paquette and C. Dumont, "Is father-child rough-and-tumble play associated with attachment or activation relationships?" Early Child Development and Care, 2012.

[39] J. L. Flanders, V. Leo, D. Paquette, R. O. Pihl, and J. R. Séguin, "Rough-and-tumble play and the regulation of aggression: an observational study of father-child play dyads," Aggressive Behavior, vol. 35, no. 4, pp. 285-295, 2009.

[40] J. L. Flanders, M. Simard, D. Paquette et al., "Rough-andtumble play and the development of physical aggression and emotion regulation: a five-year follow-up study," Journal of Family Violence, vol. 25, no. 4, pp. 357-367, 2010.

[41] M. H. Van Ijzendoorn, C. Schuengel, and M. J. BakermansKranenburg, "Disorganized attachment in early childhood: meta-analysis of precursors, concomitants, and sequelae," Development and Psychopathology, vol. 11, no. 2, pp. 225-249, 1999.

[42] L. J. Berlin, J. Cassidy, and K. Appleyard, "The influence of early attachments on other relationships," in Handbook of Attachment: Theory, Research, and Clinical Applications, J. Cassidy and P. R. Shaver, Eds., pp. 333-347, Guilford Press, London, UK, 2nd edition. 

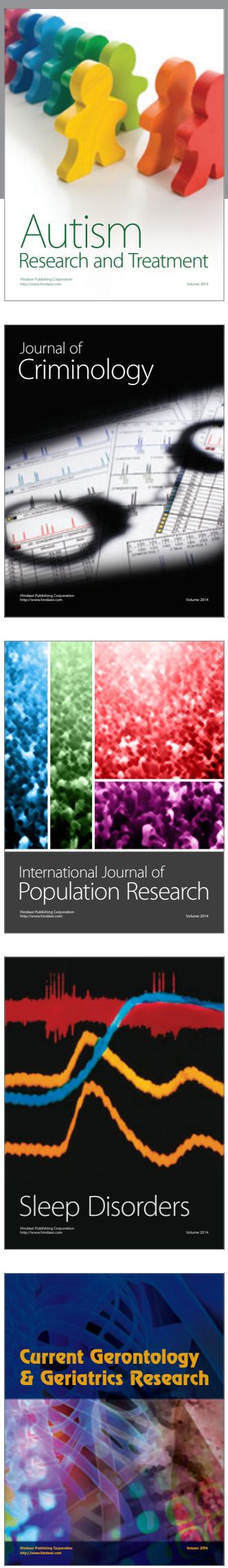
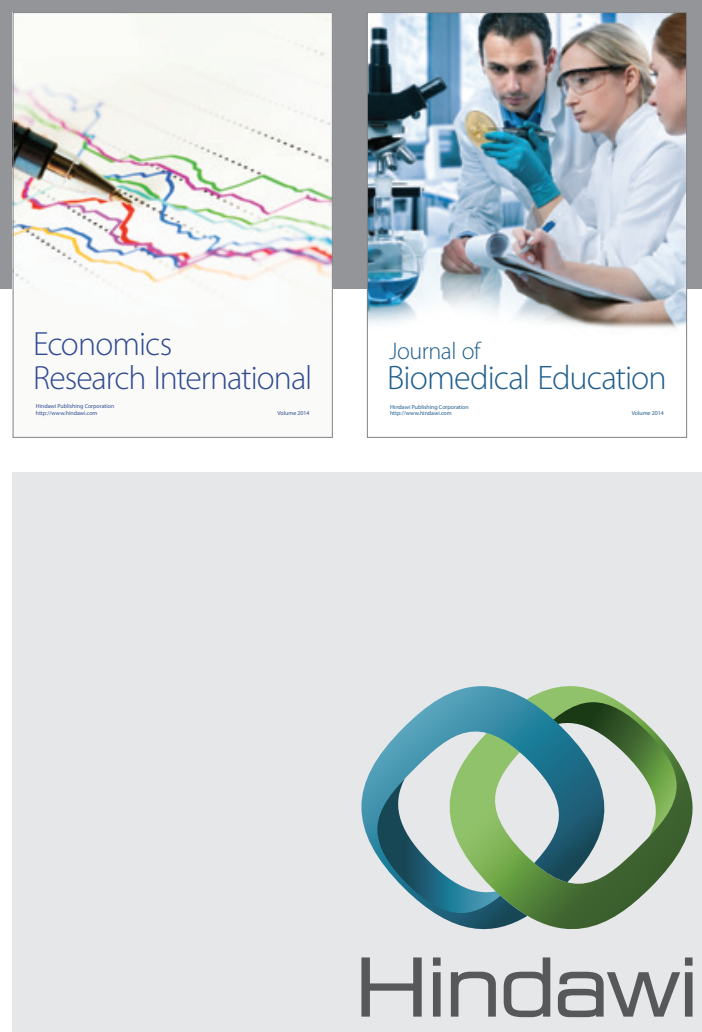

Submit your manuscripts at

http://www.hindawi.com
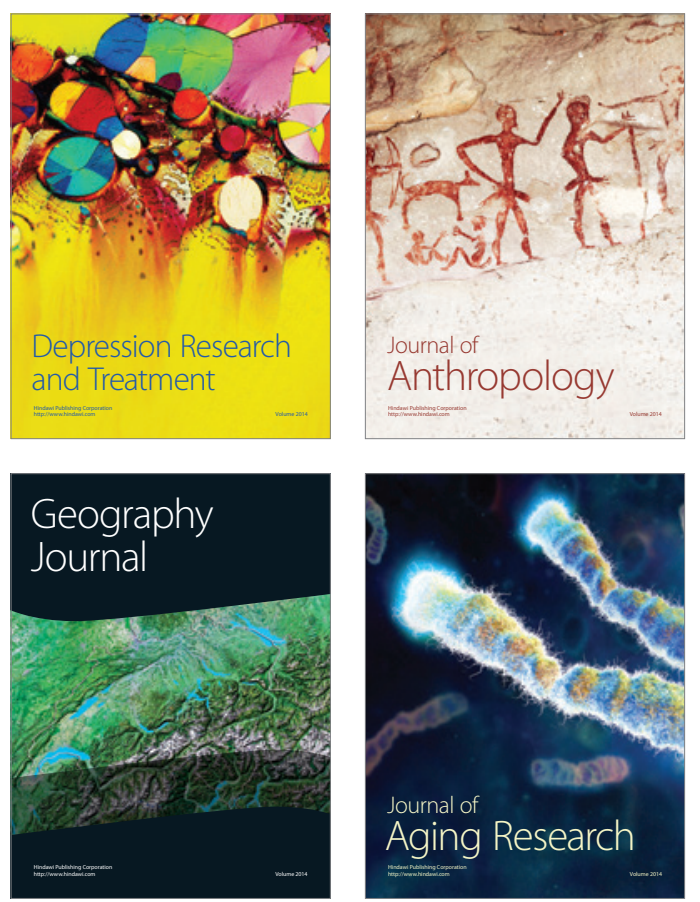
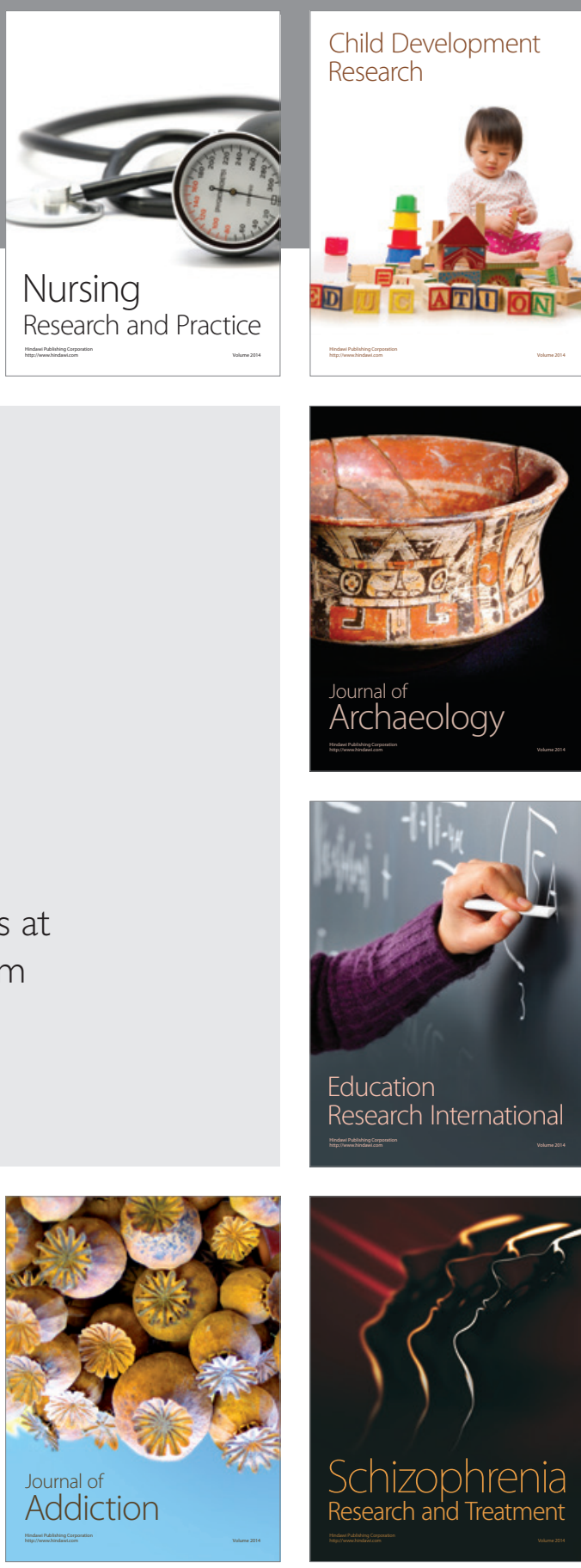

(D)
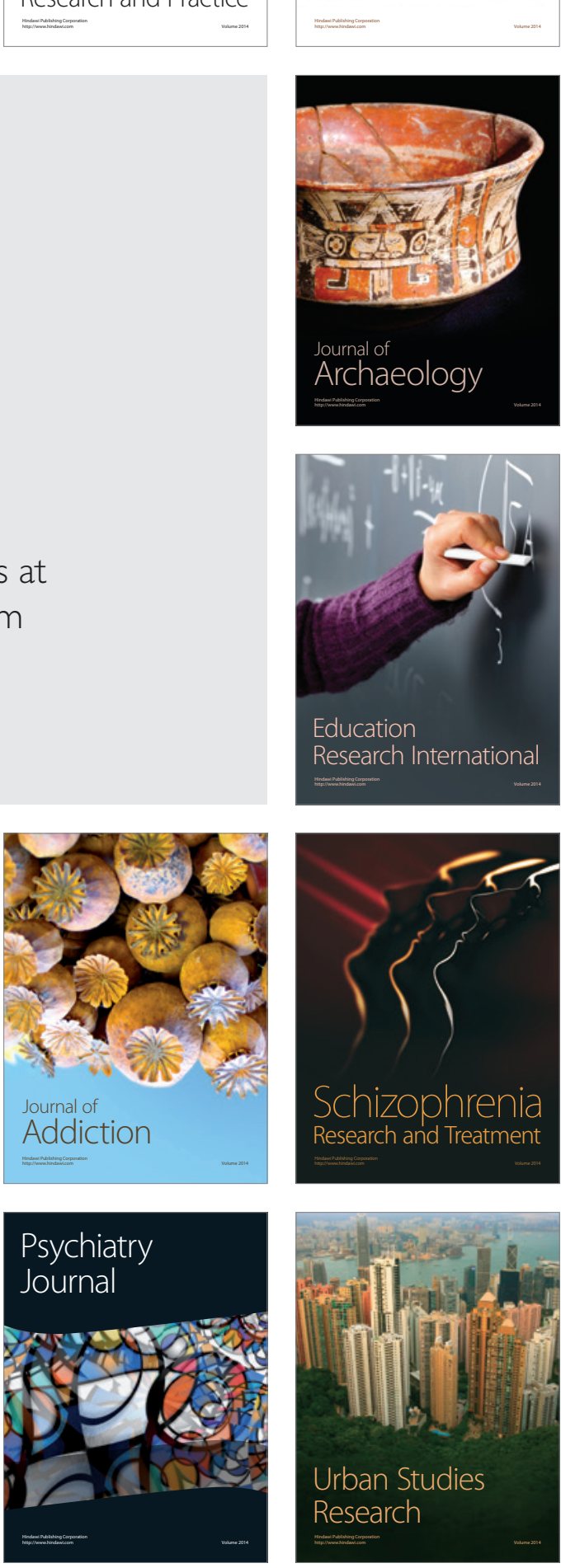